\title{
Comparison of Antimicrobial Activities of Silver Nanoparticles Biosynthesized from Some Citrus Species
}

\author{
Tenderwealth Clement Jackson*, Timma Otobong Uwah, Nonye Linda Ifekpolugo, \\ Nsikak Anthony Emmanuel
}

Department of Pharmaceutics and Pharmaceutical Technology, University of Uyo, Uyo, Nigeria

Email address:

clementjackson1@gmail.com (T. C. Jackson)

${ }^{*}$ Corresponding author

\section{To cite this article:}

Tenderwealth Clement Jackson, Timma Otobong Uwah, Nonye Linda Ifekpolugo, Nsikak Anthony Emmanuel. Comparison of Antimicrobial Activities of Silver Nanoparticles Biosynthesized from Some Citrus Species. American Journal of Nano Research and Applications.

Vol. 6, No. 2, 2018, pp. 54-59. doi: 10.11648/j.nano.20180602.12

Received: May 18, 2018; Accepted: June 14, 2018; Published: July 7, 2018

\begin{abstract}
Synthesis of nanoparticles was done by green method. Silver nitrate was used as the silver precursor, while the fruit juices of the citrus fruits (Citrus sinensis, Citrus limetta, Citrus aurantifolia, Citrus paradisi) were used as reducing and stabilizing agents. The nanoparticle formation was confirmed with the visible colour change from colourless to characteristic reddish brown. the surface plasmon resonance peak was at 451 and $452 \mathrm{~nm}$ for the silver nanoparticles The antimicrobial activities of these nanoparticles were studied against Escherichia coli, Staphylococcus aureus, Pseudomonas aeruginosa and Bacillus subtilis. Generally, MIC values of the samples against the microorganism tested ranged from $25-100 \mathrm{mg} / \mathrm{ml}$. Pseudomonas aeruginosa was the most sensitive (while Staphylococcus aureus and Bacillus subtilis were the least sensitive to the silver nanoparticles).
\end{abstract}

Keywords: Silver Nanoparticles, Green Method, Characterization, Antimicrobial

\section{Introduction}

The use of plants for the preparation of nanoparticles has gained more relevance in the past decade as the technique is simple and involves the use of plants extracts which contain biomolecules of medicinal value [1]. Nanoparticles synthesis in recent years has received considerable attention due to their special features and potential applications [2]. Silver, gold and other metal common nanoparticles, nanoclusters, nanowires and related nanostructures have received tremendous attention owing to their unique catalytic, electrical, magnetic and thermal properties. Nanosilver has immense applications in the field of detection, diagnostics, therapeutics, and antimicrobial activity [3]. Various chemical and physical methods have been developed to prepare silver nanoparticles (AgNPS). Among them, the chemical reduction is the most widely used. These approaches are usually associated with the use of hazardous chemicals such as reducing agent, stabilizers, and organic solvent. These approaches are usually associated with the use of hazardous chemicals such as reducing agent, stabilizers, and organic solvents. This may also involve special requirements for the employed techniques such as high energy radiation and microwave irradiation [4]. Many of these methods are either expensive or involve the use of harmful chemicals. Therefore, there is an increasing need to develop ecofriendly, non-toxic and cost effective methods for the preparation of AgNPs without the application of toxic chemicals and special equipment. Recently, the biological approach using microorganisms and plant extracts have become valuable alternatives to chemical synthesis. Synthesis of silver nanoparticles have been carried out using Nicotiana tobaccum [5], Cinnamomum camphora [6], Murraya koenigii [7], Eriobotrya japonica leaf extract, and even enzymes. In spite of all these researches, there is dearth of information on the synthesis of silver nanoparticles using the juice extract of some citrus species at a time; and comparison of their antimicrobial activities. The present 
study illustrates the biosynthesis of silver nanoparticles from citrus fruits extracts. Characterization of silver nanoparticles was done using UV-visible spectroscopy which gave a preliminary confirmation of silver nanoparticles.

\section{Materials and Methods}

\subsection{Materials}

Orange fruits, lemon fruits, lime fruits, grape fruits, the silver nitrate( Sigma Aldrich, USA), Mueller-Hinton broth was used as culture media. other chemicals and reagent were of analytical grade.

Organisms used include: Staphylococcus aureus, Escherichia coli, and Bacillus subtilis, Pseudomonas aeruginosa. These were collected from St. Luke's hospital laboratory and microbiology post graduate laboratory, University of Uyo, Uyo.

\subsection{Method}

\subsubsection{Extraction of Juice from the Fruits}

Citrus sinensis, Citrus paradasi, Citrus linnet, and Citrus limon were collected from the local market in Uyo. They were then washed thoroughly using distilled water to remove the dust particles adhering to the surface of the fruits peel. Thereafter, the clean and freshly ripe fruits were cleaned using a clean white towel and then cut into equal halves and each half was squeezed carefully and the juice was collected using a clean $100 \mathrm{ml}$ beaker. The extract was filtered through a clean filter paper. The filtrate was collected and stored in a clean $50 \mathrm{ml}$ beaker and covered with an aluminum foil.

\subsubsection{Preparation of Silver Nitrate Solution}

About $0.01 \mathrm{~g}$ of silver nitrate $\left(\mathrm{AgNO}_{3}\right)$ was weighed using an electronic weighing balance into a clean $100 \mathrm{ml}$ beaker and $10 \mathrm{ml}$ of distilled water was measured with a $10 \mathrm{ml}$ beaker and added to the $0.01 \mathrm{~g}$ silver nitrate to form $1 \%$ silver nitrate.

\subsubsection{Synthesis of Silver Nanoparticles}

About $0.1 \mathrm{~g}$ of silver nitrate $\left(\mathrm{AgNO}_{3}\right)$ was weighed using an electronic weighing balance into a clean $10 \mathrm{ml}$ beaker and $10 \mathrm{ml}$ of distilled water was measured with a $10 \mathrm{ml}$ beaker and added to the $0.01 \mathrm{~g}$ silver nitrate to form $1 \%$ silver nitrate.

The $1 \%$ silver nitrate was stirred for few minutes using the magnetic stirrer and the fruit extract was added dropwise with $10 \mathrm{ml}$ syringe until a brown coloration was observed. The resultant mixture was covered with aluminum foil and used for determination of antimicrobial activity of the silver nanoparticles against Gram negative (Escherichia coli, Pseudomonas aeruginosa) and Gram positive microorganisms (Staphylococcus aureus, Bacillus subtilis).

\subsubsection{Antimicrobial Activity of Silver Nanoparticles Biosynthesized from the Juice of Lime, Lemon, Orange and Grape Fruits \\ Collection of microbial isolates}

These isolates; Escherichia coli, Pseudomonas aeruginosa, Staphylococcus aureus, Bacillus subtilis were collected from St. Luke's hospital laboratory and microbiology post graduate laboratory, University of Uyo, Uyo. They were purified by sub culturing several times to obtain pure cultures. Few biochemical tests were carried out to confirm these isolates before being used for the work. The biochemical tests include; Coagulase test, Mannitol salt agar test, Indole test, Oxidase test, Citrate test, Staining test.

Dilution of test isolates before inoculation

The pure cultures of these test organisms were inoculated into sterile peptone water and incubated for 24 hours at $37^{\circ} \mathrm{C}$. Gram positive isolates i.e. Staphylococcus aureus and Bacillus subtilis were serially diluted to factor 3 using tenfold serial dilution and Gram negative isolates i.e. Pseudomonas aeruginosa and Escherichia coli were diluted up to factor 5 using tenfold serial dilution. These were carried out to standardize the inoculum size.

Screening of the silver nanoparticles for antimicrobial activity.

The silver nanoparticles biosynthesized from the juice of lime, lemon, grape and orange were screened for antimicrobial activity using the agar well diffusion method.

A quantity of $0.1 \mathrm{ml}$ of each of the test organisms were aseptically spread on the surface of the Muller-Hinton agar plate using sterile bench Hockey stick. These plates were left on the bench for thirty minutes to prediffuse into the medium. A sterile cork borer of $5 \mathrm{~mm}$ was used to bore holes on the agar plates. The silver nanoparticles concentration was graded as $500 \mathrm{mg} / \mathrm{ml}, 400 \mathrm{mg} / \mathrm{ml}, 300 \mathrm{mg} / \mathrm{ml}, 200 \mathrm{mg} / \mathrm{ml}$, $100 \mathrm{mg} / \mathrm{ml}$. About $0.5 \mathrm{ml}$ volume of each diluted silver nanoparticle was used to fill the agar wells made in the Muller-Hinton agar plates. The plates were allowed to stand for one hour to allow the extract to diffuse into the medium.

$1 \%$ Silver nitrate was used as control. All plates were incubated at $37^{\circ} \mathrm{C}$ for $24-48$ hours.

Antimicrobial activities of the silver nanoparticles and the control against microbial isolates were determined by measuring the inhibition zone diameter in $\mathrm{cm}$.

Determination of Minimum Inhibitory Concentration (MIC)

Different concentration of the silver nanoparticles; $200 \mathrm{mg} / \mathrm{ml}, 100 \mathrm{mg} / \mathrm{ml}, 50 \mathrm{mg} / \mathrm{ml}, 25 \mathrm{mg} / \mathrm{ml}$ were prepared and mixed with the medium and the organisms were streaked on the plates and incubated for 24 hours at $37^{\circ} \mathrm{C}$. The minimum inhibitory concentration was determined by checking the plate for the line of streaking of the minimum concentration of the silver nanoparticle without growth.

\section{Results and Discussion}

\subsection{Results}

The results are shown in figures 1 to 14 beolw 


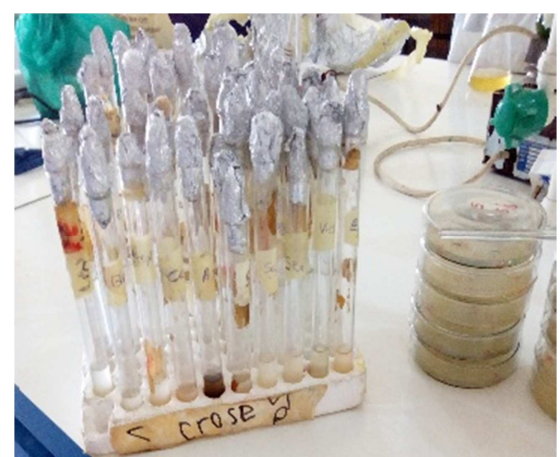

Figure 1. Ten fold serial dilution of the four test organisms: Escherichia coli, Pseudomonas aeruginosa, Bacillus subtilis, Staphylococcus aureus.

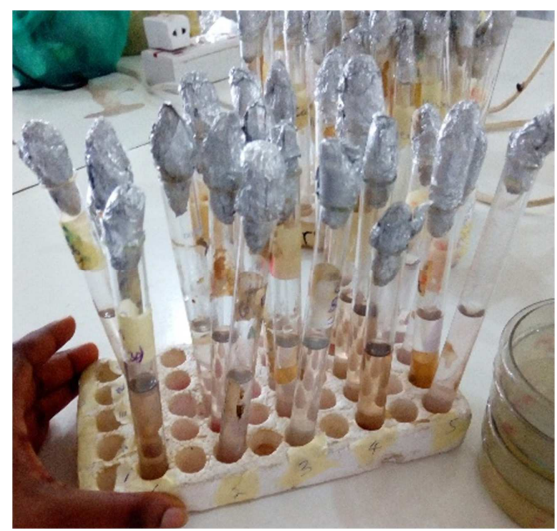

Figure 2. Dilution of the silver nanoparticles biosynthesized from orange, lemon, grape and lime for determination of MIC and IZD.

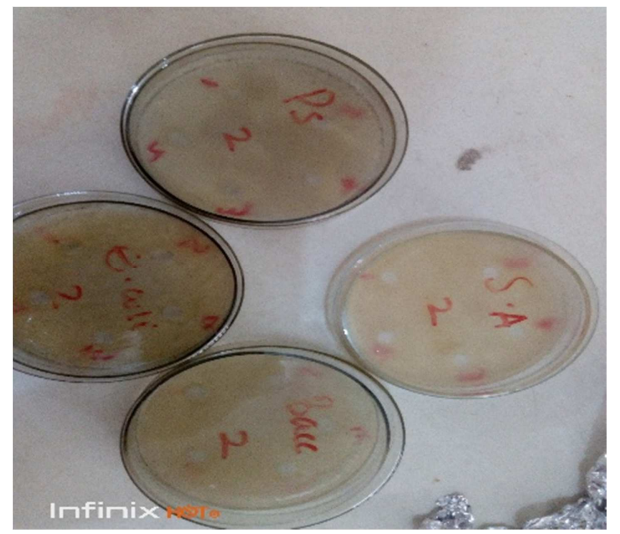

Figure 3. Plate showing the IZD of silver nanoparticles synthesized from grape fruit juice.

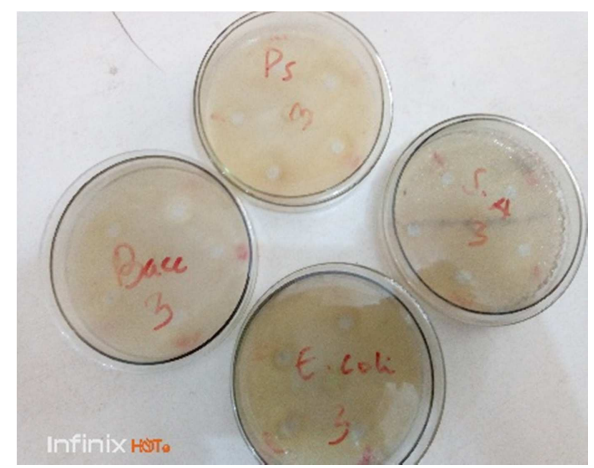

Figure 4. Plate showing the IZD of silver nanoparticles synthesized from orange fruit juice.

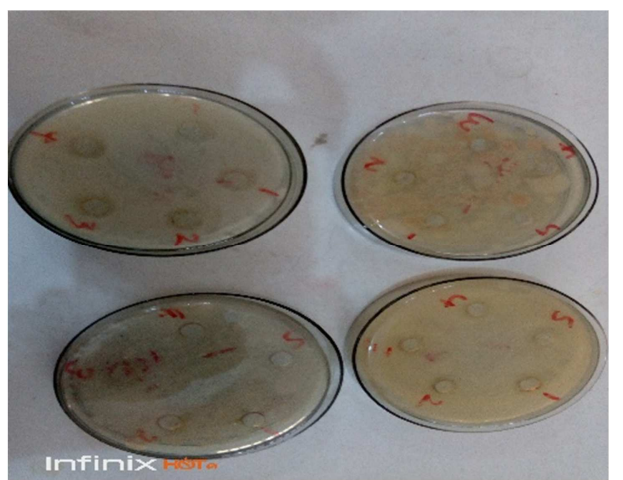

Figure 5. Plate showing the IZD of silver nanoparticles synthesized from lime fruit juice.

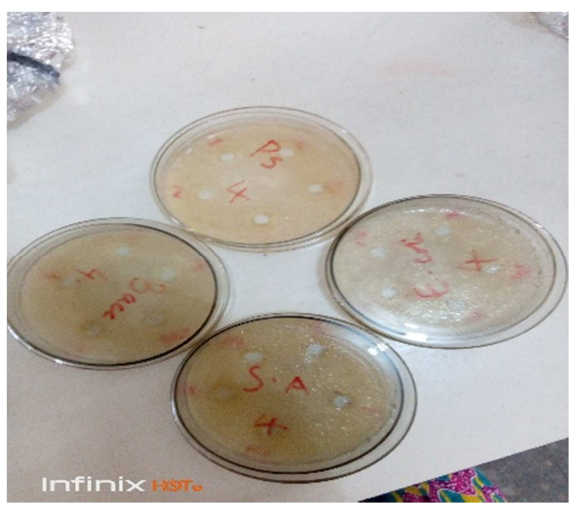

Figure 6. Plate showing the IZD of silver nanoparticles synthesized from lemon fruit juice.

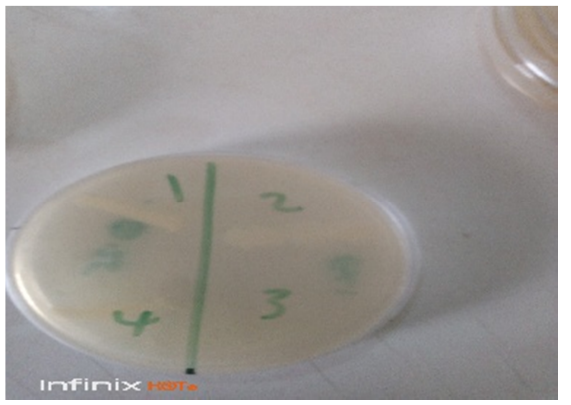

Figure 7. Plate showing the MIC of $1 \%$ silver nitrate.

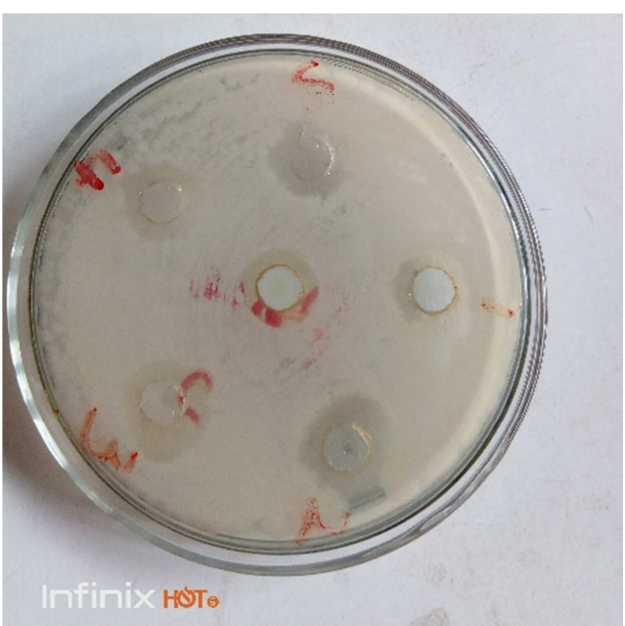

Figure 8. Plates showing IZD for 1\% silver nitrate. 


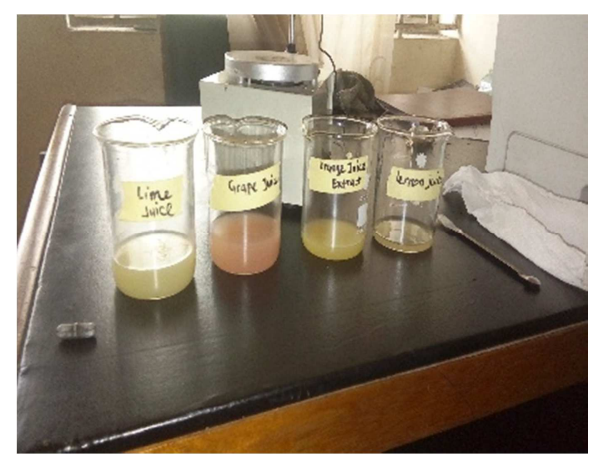

Figure 9. Juice obtained from lime, lemon, orange and grape fruits.

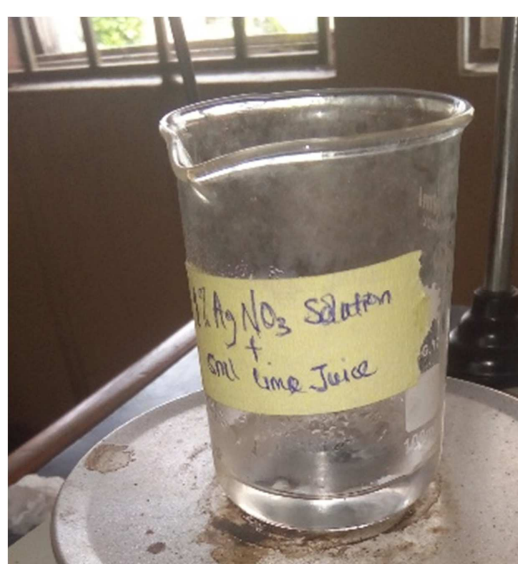

Figure 10. Silver nanoparticles biosynthesized from lime juice.

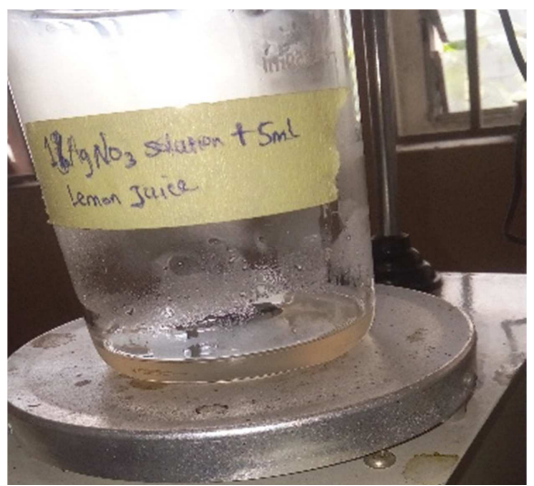

Figure 11. Silver nanoparticles biosynthesized from lemon juice.

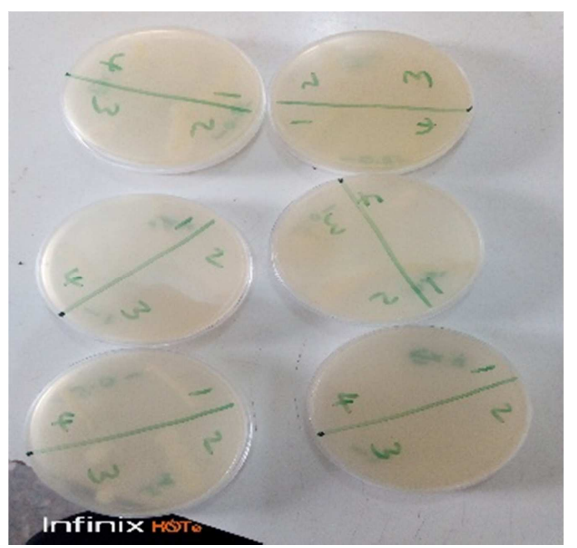

Figure 12. Plate showing the MIC of silver nanoparticles biosynthesized from lime, grape, orange, and lemon fruit juice.

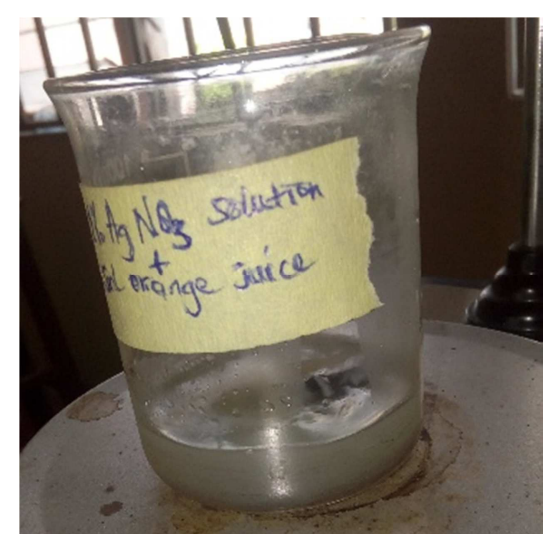

Figure 13. Silver nanoparticles biosynthesized from orange juice.

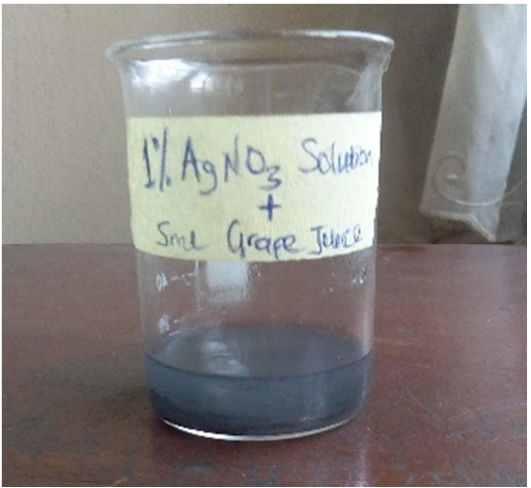

Figure 14. Silver nanoparticles biosynthesized from grape juice.

Table 1. Characterization of synthesized nanoparticles is shown in the table below.

\begin{tabular}{lllll}
\hline BATCHES & $\begin{array}{l}\mathbf{1} \% \\
\text { AgNO }_{3}\end{array}$ & $\begin{array}{l}\text { FRUIT } \\
\text { JUICE } \\
\text { EXTRACT }\end{array}$ & $\begin{array}{l}\text { COLOR } \\
\text { CHANGE }\end{array}$ & $\begin{array}{l}\text { SPR } \\
\text { PEAK } \\
(\mathbf{n m})\end{array}$ \\
\hline Lime extract & $2.5 \mathrm{ml}$ & $5 \mathrm{ml}$ & Reddish brown & $452 \mathrm{~nm}$ \\
Grape extract & $2.5 \mathrm{ml}$ & $5 \mathrm{ml}$ & Reddish brown & $451 \mathrm{~nm}$ \\
Orange extract & $2.5 \mathrm{ml}$ & $5 \mathrm{ml}$ & Reddish brown & $453 \mathrm{~nm}$ \\
Lemon extract & $2.5 \mathrm{ml}$ & $5 \mathrm{ml}$ & Reddish brown & $451 \mathrm{~nm}$ \\
\hline
\end{tabular}

\subsubsection{Minimum Inhibitory Concentration}

Table 2. The Minimum Inhibitory Concentrations of Silver nanoparticles biosynthesized from juices of grape, lime, lemon and orange fruits were as follows.

\begin{tabular}{lllll}
\hline ISOLATES & LIME & GRAPE & ORANGE & LEMON \\
\hline $\begin{array}{l}\text { Staphylococcus } \\
\text { aureus }\end{array}$ & $100 \mathrm{mg} / \mathrm{ml}$ & $100 \mathrm{mg} / \mathrm{ml}$ & $100 \mathrm{mg} / \mathrm{ml}$ & $100 \mathrm{mg} / \mathrm{ml}$ \\
$\begin{array}{l}\text { Bacillus subtilis } \\
\text { Escherichia coli }\end{array}$ & $50 \mathrm{mg} / \mathrm{ml}$ & $100 \mathrm{mg} / \mathrm{ml}$ & $50 \mathrm{mg} / \mathrm{ml}$ & $50 \mathrm{mg} / \mathrm{ml}$ \\
$\begin{array}{l}\text { Pseudomonas } \\
\text { aeruginosa }\end{array}$ & $25 \mathrm{mg} / \mathrm{ml}$ & $50 \mathrm{mg} / \mathrm{ml}$ & $100 \mathrm{mg} / \mathrm{ml}$ & $50 \mathrm{mg} / \mathrm{ml}$ \\
\hline
\end{tabular}

\subsection{Discussion}

Figure 1 shows the ten fold serial dilution of the four test organisms: Escherichia coli, Pseudomonas aeruginosa, Bacillus subtilis, Staphylococcus aureus while Figure 2 displays the dilution of the silver nanoparticles biosynthesized from orange, lemon, grape and lime prior to the determination of inhibition zone diameter ( IZD) and Mininmum inhibitory concentration (MIC). 
Plate showing the IZD of silver nanoparticles synthesized from grape fruit juice are depicted in Figure 3, while Figure 4 revealed Plate showing the IZD of silver nanoparticles synthesized from orange fruit juice. Figure 5: Plate showing the IZD of silver nanoparticles synthesized from lime fruit juice. Figure 6: Plate showing the IZD of silver nanoparticles synthesized from lemon fruit juice. Figure 7: Plate showing the MIC of $1 \%$ silver nitrate. Figure 8 : Plates showing IZD for $1 \%$ silver nitrate. Figure 9: Juice obtained from lime, lemon, orange and grape fruits.

Figures 10 to 11 and 13 to 14 show colour change observed when the nanoparticles were formed for lime. Lemon, orange and grape juice extracts respectively in that order. There was characteristic change from colourless to orange and lastly reddish brown

\subsubsection{Formation of Silver Nanoparticles}

Reduction of silver ions into silver nanoparticles during exposure to plant extracts was observed as a result of the colour change from colourless to reddish brown. The colour change is due to the Surface Plasmon Resonance (SPR) phenomenon. The metal nanoparticles have free electrons, which give the SPR absorption band, due to the combined vibration of electrons of metal nanoparticles in resonance with light wave.

The reduction of silver nitrate to silver nanoparticles was very rapid (about 3 minutes) with the addition of $5 \mathrm{ml}$ of grape juice and orange juice but the formation of silver nanoparticles with $5 \mathrm{ml}$ of lemon juice took about 15 minutes and that of $5 \mathrm{ml}$ of lime juice took approximately 25 minutes. From the result, it can be inferred that formation of silver nanoparticles is rapid with grape and orange juice than with lemon and lime juice.

\subsubsection{UV Vis Spectroscopy}

The spectra for the silver nanoparticles range from 451 to $453 \mathrm{~nm}$. Surface Plasmon resonance within thiswavelength range usually indicates silver nanoparticle formation $[8,9]$

\subsubsection{Antimicrobial Activity of Silver Nanoparticles Biosynthesized from the Juice of Lemon, Lime, Grape and Orange Fruits}

Silver nanoparticles biosynthesized from the juice of lemon, lime, grape and orange fruits as well as $1 \%$ silver nitrate showed broad spectrum antibacterial activities against both Gram negative and Gram positive bacteria; Staphylococcus aureus, Escherichia coli, Bacillus subtilis, Pseudomonas aeruginosa. Silver nanoparticles synthesized using lime juice were found to be more active against Escherichia coli and Staphylococcus aureus [10].

Silver nanoparticles synthesized using orange juice were found to be more active against Escherichia coli and Staphylococcus aureus [10].

Silver nanoparticles synthesized using orange juice were found to be active against Pseudomonas aeruginosa.

Silver nanoparticles synthesized using orange juice were found to be active against Bacillus subtilis.

Silver nanoparticles synthesized using lemon juice were found to be active against Pseudomonas aeruginosa, Bacillus subtilis, Escherichia coli, Staphylococcus aureus.

Silver nanoparticles synthesized using grape juice were found to be active against Bacillus subtilis, Staphylococcus aureus [11].

Silver nanoparticles synthesized using grape juice were found to be active against Pseudomonas aeruginosa, Bacillus subtilis, Escherichia coli, Staphylococcus aureus.

\subsubsection{Minimum Inhibitory Concentration}

The Minimum Inhibitory Concentrations were determined. The concentrations used were

$200 \mathrm{mg} / \mathrm{ml}, 100 \mathrm{mg} / \mathrm{ml}, 50 \mathrm{mg} / \mathrm{ml}$ and $25 \mathrm{mg} / \mathrm{ml}$ of the silver nanoparticles.

The Minimum Inhibitory Concentration of Silver nanoparticles from lime juice against Pseudomonas aeruginosa, Bacillus subtilis, Escherichia coli, Staphylococcus aureus were $25 \mathrm{mg} / \mathrm{ml}, 50 \mathrm{mg} / \mathrm{ml}, 50 \mathrm{mg} / \mathrm{ml}$ and $100 \mathrm{mg} / \mathrm{ml}$ respectively.

The Minimum Inhibitory Concentration of Silver nanoparticles from grape juice against Pseudomonas aeruginosa, Bacillus subtilis, Escherichia coli, and Staphylococcus aureus were $25 \mathrm{mg} / \mathrm{ml}, 100 \mathrm{mg} / \mathrm{ml}, 50 \mathrm{mg} / \mathrm{ml}$ and $100 \mathrm{mg} / \mathrm{ml}$ respectively.. Thus, lime and grape derived silver nanoparticles had similar $(\mathrm{P}>0.05)$ antimicrobial activity against Pseudomonas aeruginosa, Escherichia coli and Staphylococcus aureus but significantly $(\mathrm{p}<0.05)$ different activity against Bacillus subtilis

The Minimum Inhibitory Concentration of Silver nanoparticles from orange juice against Pseudomonas aeruginosa, Bacillus subtilis, Escherichia coli, Staphylococcus aureus were $50 \mathrm{mg} / \mathrm{ml}, 100 \mathrm{mg} / \mathrm{ml}, 100 \mathrm{mg} / \mathrm{ml}$ and $100 \mathrm{mg} / \mathrm{ml}$ respectively. The Minimum Inhibitory Concentration of Silver nanoparticles from lemon juice against Pseudomonas aeruginosa, Bacillus subtilis, Escherichia coli, Staphylococcus aureus were $50 \mathrm{mg} / \mathrm{ml}$, $50 \mathrm{mg} / \mathrm{ml}, 50 \mathrm{mg} / \mathrm{ml}$ and $100 \mathrm{mg} / \mathrm{ml}$ respectively.

From the results, it could be inferred that Pseudomonas aeruginosa is most susceptible to silver nanoparticles biosynthesized from lime and grape juice as these nanoparticles showed antimicrobial activity at concentrations as low as $25 \mathrm{mg} / \mathrm{ml}$. This was closely followed by orange and grape derived silver nanoparticles with MIC of $50 \mathrm{mg} / \mathrm{mL}$. Staphylococcus aureus was the least sensitive to all the nanoparticles derived from the citrus fruits with MIC of 100 $\mathrm{mg} / \mathrm{mL}$ for all silver nanoparticles derived from lime, grape, orange and lemon extracts.

the silver nanoparticles showed significantly $(\mathrm{P}<0.05)$ antimicrobial properties when compared to either silver nitrate alone or the citrus fruits $[12-15]$

\section{Conclusion}

The silver nanoparticles synthesized from the juice of lime, lemon, grape and orange juices showed broad spectrum antimicrobial activity against both Gram positive and Gram negative organisms (Pseudomonas aeruginosa, Bacillus subtilis, Escherichia coli, and Staphylococcus aureus). 
These silver nanoparticles can serve as drug delivery system. Antibiotics with resistance problem can be loaded on these silver nanoparticles for effective therapy.

\section{Conflict of Interests}

The authors declared no conflict of interest.

\section{Acknowledgements}

The authors are grateful to Tertiary Education Trust Fund (TETfund), Nigeria.

\section{References}

[1] Roy S, Das T. K., (2015). Plant mediated green synthesis of silver nanoparticles. A Review. Int. J. Plant Biol. Res. 3(3):1044-1055.

[2] Sathishkumar M, Sneha K, Won S. W., Cho C. W., Kim S, Yun Y. S. (2009). Cinnamon zeylanicum bark extract and powder mediated green synthesis of nano-crystalline silver particles and its bactericidal activity. Colloids Surf. B. Biointerfaces 73(2):332-338.

[3] Sachin S, Anupama P, Meenal K (2012). Biosynthesis of silver nanoparticles by marine bacterium, Idiomarine $S p$. PR-58-5. Bull. Mater. Sci. 35 (7): 1201-1205.

[4] Rao B, Tang R. C., (2017). Green synthesis of silver nanoparticles using aqueous Eriobotyra japonica leaf extract. Adv. Nat. Sci. Nanosci. Nanotechnol. 8(2017) 015014 (8p).

[5] Kumar P, Suranjit P, Darshit P, Patel P, Selvaraj K, Prasad S (2011). Biogenic synthesis of silver nanoparticles using Nicotiana tobaccum leaf extract and study of their antibacterial effect. Afr. J. Biotechnol. 10(41):8122-8130.

[6] Xin Y, Qingbiao L. I., Huixuan W, Jiale H, Liqin L, Wenta W, Daohua S, Yuanbo S, James B, Luwei H, Yuanpeg W, Ning H, Lishan J (2010). Green synthesis of palladium nanoparticles using broth of Cinnamomum camphora leaf. J. Nanopart. Res. 12: $1589-1598$.
[7] Jackson T. C., Agboke A, Jackson I, Ekpuk E (2016). Biosynthesis of silver nanoparticles using Murraya koenigii and Acacia Gum. Int. J. Nanomed. 8: 1507-1516.

[8] Prabhu N., Raj T., Gowri D., Yamuna K,. Ayisha S., Joseph S., and Puspha D (2010) Synthesis of silver phyto nanoparticles and their antibacterial efficacy. Dig. J. Nanomat. Bios; 5(1); 185.

[9] Vivekanandhan S, Misra M, Mohanty AK (2010) Novel Glycine Max (soyabean) leaf extract based biological process for the functionalization of carbon nanotubes with silver nanoparticles. Nanosci. Nanotechnol. let 2(3): 240.

[10] Hugund BS, Dhulappanavar GR, Ayachit NH (2015) Comparative Evaluation of Antibacterial Activity of Silver Nanoparticles Biosynthesized using Fruit Juices. J Nanomed Nanotechnol 2015, 6:271. doi:10.4172/2157-7439.1000271

[11] CLSI, Performance Standards for Antimicrobial Disk Susceptibility Tests, Approved Standard, $7^{\text {th }}$ Edition; CLSI document MO2-A11. Clinical and Laboratory Standards Institute, 950 West Valley Road, Suite 2500, Wayne, Pennsylvania 19087, USA, 2012.

[12] Vijayakumar, M., et al. (2013) Biosynthesis, Characterisation and Anti-bacterial Effect of Plant-Mediated Silver Nanoparticlles Using Artemisia nilagirica. Industrial Crops and Products, 41, 235-240.

[13] Alzahrani, E. and Welham, K. (2014) Optimization Preparation of the Biosynthesis of Silver Nanoparticles Using Watermelon and Study of Its Antibacterial Activity. International Journal of Basic and Applied Sciences, 3, 392400.

[14] Alzahrani, E. (2015) Ecofriendly Production of Silver Nanoparticles from Peel of Tangerine for Degradation of Dye. World Journal of Nano Science and Engineering, 5, 10-16.

[15] Sudha, M., Murugan, B. (2015) Orange Seed Mediated Green Synthesis Silver Nanoparticles. International Journal of Biosciences and Nanosciences. Volume 2 (11), 2015, pp. 215220. 